\title{
EKSPLORASI KEMAMPUAN PEMECAHAN MASALAH MATEMATIKA DITINJAU DARI TIPE KEPRIBADIAN IDEALIS DAN RASIONAL MAHASISWA UNIVERSITAS DARUSSALAM AMBON
}

\author{
Kasriana $^{1}$, Rasid Ode ${ }^{2}$ \\ Prodi Pendidikan Matematika Universitas Darussalam Ambon \\ e-mail:kasriana@unidar.ac.id
}

\begin{abstract}
This study aims to described students in solving problems based on personality type use instruments, personality type, problem solving and interview. The results of the study show:(1) understand the problems the subject of idealist only record that asked; (2) was making plans the subject could detect formula; (3) carry out a plan the subject of using formulas were formerly, although one measure. (1) understand the problems the subject type rational not have inscribed requirements enough and the requirements necessary; (2) was making plans subject to determine the steps the; (3) implement plan, problem solving skilled in algorithms and accuracy of. Basically type idealisdan rational capable of being searched the solution of given problem but not wrote with complete steps resolution.
\end{abstract}

Keywords : idealist personality, rational personality, solving problems

\section{PENDAHULUAN}

Peradaban manusia bukanlah barang jadi yang jatuh dari langit yang diwarisi secara turun-temurun. Peradaban adalah suatu perjuangan manusia dari abad ke abad dengan menggunakan segala kemampuannya, baik dari lahir maupun yang diperoleh dari pengalaman sebagai hasil budi daya dan rekayasa dalam menghadapi segala hambatan dan tantangan serta keterbatasanketerbatasan yang dijumpai sepanjang perjalanan hidupnya. Dalam proses itu, pendidikan senantiasa merupakan faktor yang menentukan baik dalam arti peranan, maupun dalam kegunaannya. oleh karena itu dapatlah dipahami kalau immanuel kant (dalam Sahabuddin 2007), seorang filosof jerman yang termahsyur mengatakan bahwa manusia hanya dapat menjadi manusia karena dan oleh pendidikan.

Sistem pendidikan nasional menyatakan bahwa tujuan pendidikan adalah untuk pengembangan potensi siswa untuk menjadi religius dan bertaqwa kepada Tuhan, berakhlak mulia, sehat, berilmu, cakap, kreatif, mandiri,dan menjadi warga negara yang demokratis dan bertanggung jawab (Upu, 2015). Pelajaran 
matematika adalah salah satu pelajaran yang diajarkan mulai dari sekolah dasar, sekolah menengah, sampai perguruan tinggi. Hal itu tidak berlebihan, sebab dengan menguasai dan memahami matematika maka diharapkan bangsa indonesia dapat menguasai dan ikut mengembangkan teknologi. pemecahan masalah merupakan bagian yang penting dalam pembelajaran matematika, karena dengan pemecahan masalah siswa dimungkinkan memperoleh pengalaman menggunakan pengetahuan serta keterampilan yang sudah dimiliki untuk diterapkan pada pemecahan masalah yang bersifat tidak rutin.

Untuk membimbing siswa agar mampu dalam memecahkan masalah matematika, seorang guru harus mampu merancang model pembelajaran. Sebuah model pembelajaran dapat sesuai dengan seorang peserta didik, namun bisa jadi tidak sesuai untuk peserta didik lain. Hal ini disebabkan oleh kenyataan bahwa setiap peserta didik adalah individu yang unik dan mempunyai karakteristik yang berbeda-beda. Beberapa hal yang dapat mempengaruhi karakteristik siswa yaitu tipe kepribadian yang dimiliki.

Pada tahun 1984, dalam bukunya Please Understand Me I dan II, David Keirsey, seorang profesor dalam bidang psikologi dari California State University, menggolongkan kepribadian menjadi 4 tipe, diantaranya Rational dan Idealis. Individu dengan tipe idealist lebih menyukai menyelesaikan tugas secara diskusi kelompok, menyukai membaca dan menulis sehingga lebih cocok jika diberi tes berbentuk uraian atau soal cerita. Individu dengan tipe rational menyukai cara belajar dengan pemecahan masalah yang kompleks, lebih suka belajar secara mandiri, serta mampu menangkap abstraksi dan materi yang memerlukan intelektualitas yang tinggi (Keirsey dan Bates, 1984).

Keirsey juga menggolongkan cara berkomunikasi baik lisan maupun tertulis menjadi dua kategori, yaitu konkret dan abstrak. Guardians dan Artisan merupakan komunikator kongkret, sedangkan rational dan idealist adalah komunikator abstrak. Komunikator kongkret lebih menyukai berbicara dan menulis tentang realita, sedangkan komunikator abstrak lebih menyukai berbicara dan menulis tentang ide-ide. Komunikator kongkret menyukai fakta, angka, bukti, sedangkan komunikator abstrak menyukai teori dan hipotesis. Komunikator kongkret berbicara dan menulis secara detail, spesifik, empiris dan faktual. Sedangkan komunikator abstrak secara skematik, umum, teoritis dan fiksi (eko siswono).

Menurut Keirsey cara memilih jalan untuk menyelesaikan masalah digolongkan menjadi dua, yaitu cooperative dan utilitarian. Guardian dan idealist termasuk dalam kategori cooperative, dimana mereka akan memilih cara yang umum digunakan dan diterima kebanyakan orang. Sedangkan artisan dan rational termasuk dalam kategori utilitarian, dimana mereka akan mencari cara yang paling efektif menurut mereka tanpa memikirkan apakah cara tersebut dapat diterima orang lain atau tidak. 
Keirsey \& Bates dalam Yuwono (2010) mendeskripsikan gaya belajar untuk masing-masing tipe kepribadian yaitu

a. Tipe Rational menyukai penjelasan yang didasarkan pada logika. Mereka mampu menangkap abstraksi dan materi yang memerlukan intelektualitas yang tinggi. Setelah diberikan materi oleh guru, biasanya Rational mencari tambahan materi melalui membaca buku. Rational menyukai guru yang dapat memberikan tugas tambahan secara individu setelah pemberian materi. Dalam menerima materi, Rational menyukai guru yang menjelaskan selain materinya, namun juga mengapa atau dari mana asalnya materi tersebut. Bidang yang disukai biasanya sains, matematika, dan filsafat, meskipun tidak menutup kemungkinan akan berhasil di bidang yang diminati. Cara belajar yang paling disukai oleh Rational adalah eksperimen, penemuan melalui eksplorasi, dan pemecahan masalah yang kompleks. Kelompok ini cenderung mengabaikan materi yang dirasa tidak perlu atau membuang waktu, oleh karenanya, dalam setiap pemberian materi, guru harus dapat meyakinkan kepentingan suatu materi terhadap materi yang lain.

b. Tipe Idealist menyukai materi tentang ide dan nilai-nilai. Lebih menyukai untuk menyelesaikan tugas secara pribadi daripada diskusi kelompok. Dapat memandang persoalan dari berbagai perspektif. Menyukai membaca, dan juga menyukai menulis. Oleh sebab itu, Idealist kurang cocok dengan bentuk tes objektif, karena tidak dapat mengungkap kemampuan dalam menulis. Kreativitas menjadi bagian yang sangat penting bagi seorang Idealist. Kelas besar sangat mengganggu Idealist dalam belajar, sebab Idealist lebih menyukai kelas kecil dimana setiap anggotanya mengenal satu dengan yang lain

\section{METODE PENELITIAN}

\section{Jenis penelitian}

Jenis penelitian ini adalah eksploratif dengan pendekatan kualitatif. Penelitian kualitatif adalah penelitian yang bertujuan untuk memahami fenomena tentang apa yang dialami oleh subjek penelitian secara holistik dan dengan cara deskriptif dalam bentuk kata-kata dan bahasa pada suatu konteks khusus yang alamiah dengan memanfaatkan berbagai metode ilmiah. Penelitian ini berusaha mengungkap secara mendalam kemampuan pemecahan masalah berdasarkan penggolongan tipe kepribadian menurut keirsey, yaitu tipe rational, dan idealist, dimana dalam memecahkan masalah mengacuh pada langkah-langkah pemecahan masalah menurut polya yaitu memahami masalah, merencanakan masalah, melaksanakan rencana, dan mengecek kembali. 


\section{Lokasi penelitian}

Penelitian ini dilaksanakan di Universitas Darussalam Ambon. Darussalam Ambon merupakan tempat peneliti mengajar sehingga akan memudahkan peneliti berkomunikasi dengan subjek nantinya.

\section{Subjek penelitian}

Subjek dalam penelitian ini adalah peserta didik semester 4 program studi pendidikan matematika Universitas Darussalam Ambon yang di pilih sebanyak 2 subjek berdasarkan tipe kepribadian idealis dan rasional.

\section{Instrumen penelitian}

Karena penelitian ini adalah penelitian kualitatif, maka peneliti adalah instrumen utama dalam pengumpulan data, yang dibantu dengan instrumen pendukung yaitu: instrumen penggolongan tipe kepribadian, instrumen lembar tugas pemecahan masalah, dan pedoman wawancara.

\section{Teknik analisis data}

Proses analisis data menggunakan model miles dan huberman (dalam sugiyono, 2012: 337-345) yang dilakukan dengan langkah sebagai berikut:

a. Menelaah seluruh data yang tersedia dari berbagai sumber, yaitu dari wawancara, pengamatan yang sudah dituliskan, dalam catatan lapangan, dan hasil tes soal matematika.

b. Data reduction (reduksi data) yaitu kegiatan yang mengacu pada proses pemilihan dan pengidentikasian data yang memiliki makna jika dikaitkan dengan masalah penelitian, yang selanjutnya membuat kode pada setiap satuan sehingga diketahui sumbernya

c. Data display (penyajian data) yaitu pengklasifikasian data, yaitu menuliskan kumpulan data yang terorganisir dan terkategori sehingga memungkinkan untuk menarik kesimpulan dari data tersebut. Data yang dikumpulkan berupa respon subjek yang menunjukkan explorasi subjek penelitian dalam mengerjakan soal-soal masalah matematika berdasarkan langkah polya

d. Membuat Coding yang bertujuan untuk memudahkan pemaparan data kemampuan penalaran siswa berprestasi matematika, maka dilakukan coding pada petikan jawaban subjek penelitian saat wawancara

e. Conclusion drawing (penarikan kesimpulan) dilakukan dengan memperhatikan hasil dari soal-soal pemecahan masalah matematika dan hasil wawancara untuk menentukan karakteristik explorasi subjek penelitian berdasarkan tipe kepribadian dan tingkat kecemasan belajarnya

\section{Prosedur Penelitian}

Secara umum tahapan-tahapan dalam penelitian ini dapat digambarkan seperti pada gambar berikut. 


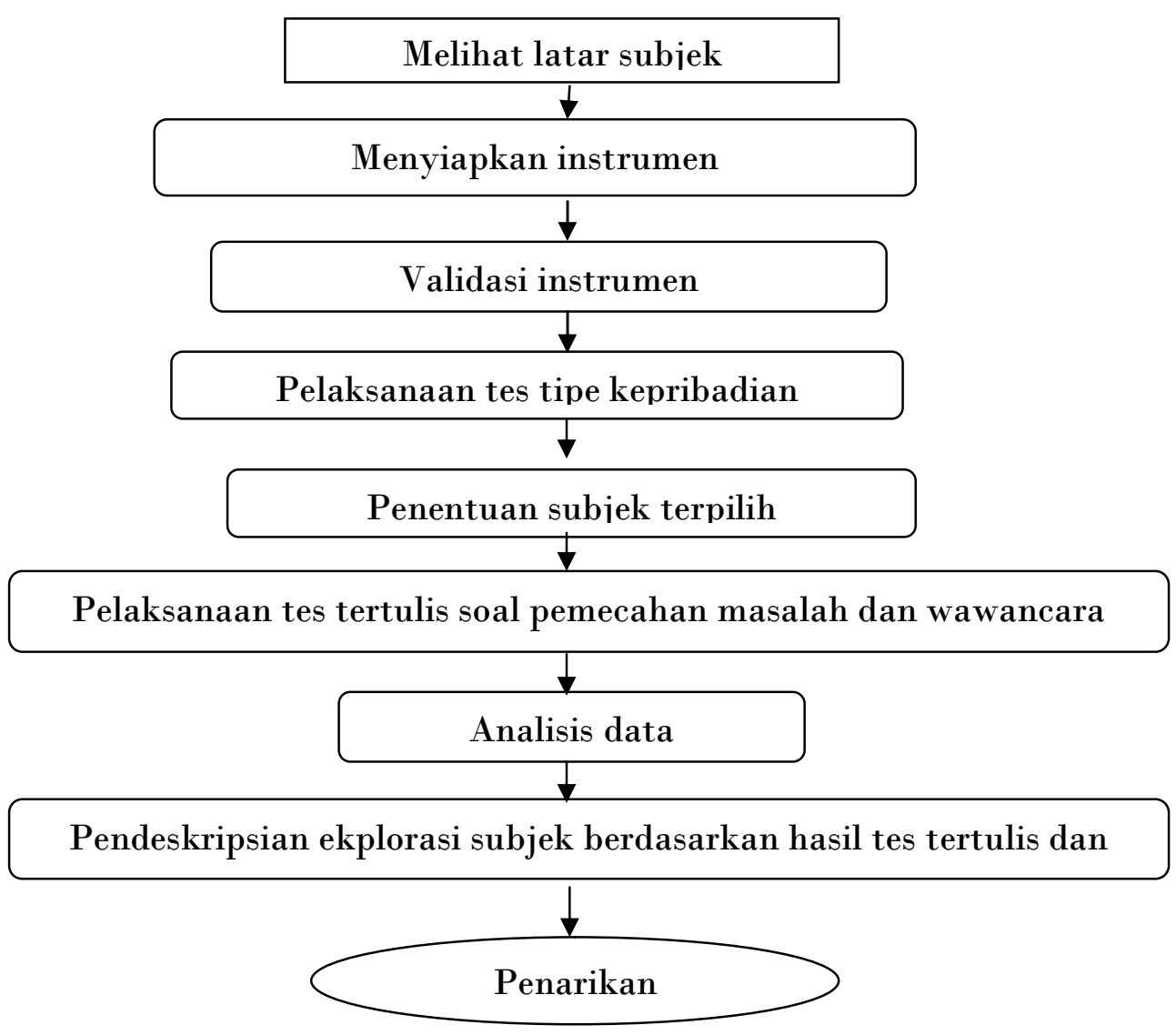

Gambar 1. Tahapan prosedur penelitian

\section{HASIL DAN PEMBAHASAN}

Berikut adalah temuan hasil penelitian kemampuan pemecahan masalah matematika siswa berdasarkan tipe kepribadian dan kecemasan belajar matematika dari 30 siswa kelas X SMA Negeri 6 Makassar, dipilih 4 siswa sebagai subjek penelitian. Pemilihan ini berdasarkan pertimbangan/pendapat guru atau pihak lain dengan memperhatikan kriteria: (1) tipe kepribadian, (2) keaktifan selama pembelajaran matematika, dan (3) dapat mengemukakan pendapat/jalan pikirannya secara lisan maupun tulisan. 
Tabel 1. Subjek penelitian

\begin{tabular}{cc}
\hline Idealist & Rational \\
\hline La Paneng Tomia (LP.T) & Yuyun Mayau (Y.M) \\
\hline
\end{tabular}

Berikut adalah temuan hasil penelitian kemampuan pemecahan masalah matematika siswa berdasarkan tipe kepribadian.

Kemampuan pemecahan masalah matematika siswa tipe idealist

Tabel 2. Kemampuan pemecahan masalah matematika siswa tipe idealist

\begin{tabular}{|c|l|l|}
\hline No & Pemecahan masalah & \multicolumn{1}{c|}{ Karakter idealist } \\
\hline 1 & Memahami masalah & Melakukan proses berfikir abstraksi \\
\hline 2 & $\begin{array}{l}\text { Membuat rencana } \\
\text { pemecahan masalah }\end{array}$ & Melakukan proses berfikir cooperative \\
\hline 3 & $\begin{array}{l}\text { Melaksanakan } \\
\text { rencana }\end{array}$ & $\begin{array}{l}\text { Melakukan proses berfikir abstraksi dan } \\
\text { menyelesaikan masalah dengan kategori cooperative }\end{array}$ \\
\hline
\end{tabular}

Kemampuan pemecahan masalah matematika siswa tipe rational.

Tabel 3. Kemampuan pemecahan masalah matematika siswa tipe rational

\begin{tabular}{|c|l|l|}
\hline No & Pemecahan masalah & \multicolumn{1}{|c|}{ Karakter rational } \\
\hline 1 & Memahami masalah & $\begin{array}{l}\text { Melakukan proses berfikir abstraksi, selalu } \\
\text { memperhatikan efisiensi dari segala hal yang } \\
\text { dilakukan sehingga subjek } R T \text { tidak menuliskan } \\
\text { dengan lengkap apa yang diketahui dan apa yang } \\
\text { ditanyakan pada soal karena hal itu sudah sangat } \\
\text { jelas }\end{array}$ \\
\hline 2 & $\begin{array}{l}\text { Membuat rencana } \\
\text { pemecahan masalah }\end{array}$ & $\begin{array}{l}\text { melakukan proses berfikir utilitarian } \\
\text { melaksanakan }\end{array}$ \\
\hline 3 & $\begin{array}{l}\text { melakukan proses berfikir abstraksi menyelesaikan } \\
\text { masalah dengan kategori utilitarian }\end{array}$ \\
\hline
\end{tabular}

Menurut keisey tipe kepribadian idealist dan tipe kepribadian rational berbeda dalam menyelesaikan masalah yang diberikan. Tipe kepribadian idealist termasuk kedalam kategori cooperative dimana mereka akan memilih cara yang umum digunakan dan diterima kebanyakan orang, sedangkan tipe kepribadian rational termasuk kedalam kategori utilitarian dimana mereka akan mencari cara yang paling efektif menurut mereka dalam menyelesaikan masalah tanpa memikirkan apakah cara tersebut dapat diterima orang lain atau tidak. 
Berikut ini disajikan contoh perbedaan pemecahan masalah berdasarkan tipe kepribadian idealist dan tipe kepribadian rational

\section{Subjek idealist}

a. Memahami masalah: pada tahap memahami masalah, L.P.T mampu menuliskan apa yang diketahui dan apa yang ditanyakan pada soal dengan jelas. Dengan melihat hasil kerja siswa pada saat tes tertulis dimana siswa mampu menuliskan apa yang diketahui dan apa yang ditanyakan dengan lengkap dan jelas menunjukkan karateristik idealist yang suka menulis.

b. Merencanakan strategi: pada tahap ini subjek L.P.T mampu mengaitkan antara hal yang diketahui dan hal yang ditanyakan untuk menentukan rumus yang tepat dalam menjawab pertanyaan. Hal ini sesuai dengan karakteristik idealist yang memproses data dengan melihat pada pola dan hubungan, meskipun saat wawancara salah menyebutkan rumus dikarenakan subjek sedikit tegang dan gugup.

c. melaksanakan rencana: pada tahap ini L.P.T menggunakan langkahlangkah yang telah disusun sebelumnya secara benar, meskipun dalam tahap penyelesaian salah dalam perhitungan. Karakteristik idealist yang muncul pada subjek yaitu cepat dalam bertindak, namun dampaknya subjek kurang hati-hati dalam melakukan perhitungan.

\section{Subjek rational}

a. Memahami masalah: subjek Y.M tidak menuliskan dengan lengkap apa yang diketahui dan apa yang ditanyakan pada soal karena hal itu sudah sangat jelas. Subjek Y.M menganggap bahwa hal segala hal harus jelas agar jelas juga bagi orang lain, hal ini sesuai dengan karakter rational. tipe ini cenderung mengabaikan hal-hal yang dirasa tidak perlu atau membuang waktu. Karena hal yang diketahui pada soal dirasa sudah jelas, maka subjek tidak menuliskannya dengan beranggapan bahwa hal yang sudah jelas bagi mereka, sudah jelas juga bagi orang lain sehingga untuk menuliskannya hanya akan membuang waktu dan tenaga. Karakteristik rational yang muncul pada subjek saat memahami masalah yaitu selalu berusaha untuk mengurangi atau membatasi penjelasannya sehingga untuk menjelaskan ide/isi fikirannya mereka memilih menggunakan gambar.

b. Merencanakan strategi: pada tahap ini subjek $Y . M$ mampu mengaitkan informasi yang ada pada soal untuk menentukan langkah penyelesaian. Karakteristik rational yang terlihat pada tahap perencanaan pemecahan masalah yaitu memproses data dengan melihat pada pola dan hubungan serta bagus dalam menganalisa

c. Melaksanakan rencana: pada tahap ini subjek $Y . M$ menggunakan langkahlangkah secara benar, serta terampil dalam algoritma dan ketepatan 
menjawab soal. Karakteristik rational yang muncul pada subjek $Y . M$ pada tahap menyelesaikan masalah yaitu "menerapkan prinsip dan konsisten".

\section{SIMPULAN}

Berdasarkan hasil analisis data dan pembahasan yang telah dikemukakan pada bab sebelumnya, maka ditarik kesimpulan penelitian sebagai berikut:

1. Dalam memahami masalah, Subjek idealist hanya menuliskan apa yang ditanyakan pada soal tanpa menuliskan apa yang diketahui; (2) dalam membuat rencana pemecahan masalah, siswa mampu mengaitkan antara hal yang diketahui dan hal yang ditanyakan dengan menggunakan rumus yang jelas; (3) dalam melaksanakan rencana pemecahan masalah, siswa menggunakan langkah-langkah yang telah disusun sebelumnya secara benar, meskipun dalam tahap penyelesaian salah dalam perhitungan.

2. Dalam memahami masalah, siswa tipe rational tidak menuliskan syarat cukup dan syarat perlu; (2) dalam membuat rencana pemecahan masalah, siswa mampu mengaitkan informasi yang ada pada soal untuk menentukan langkah penyelesaian; (3) dalam melaksanakan rencana pemecahan masalah, siswa mampu menggunakan langkah-langkah secara benar, serta terampil dalam algoritma dan ketepatan menjawab soal.

\section{SARAN}

Berdasarkan kesimpulan pada penelitian ini, dalam pembelajaran pemecahan masalah matematika berdasarkan langkah-langkah Polya disarankan kepada guru matematika sebagai berikut.

1. Perlu diadakan penelitian lebih lanjut tentang jumlah atau persentase masingmasing tipe kepribadian siswa dan tingkat kecemasan belajarnya untuk dapat dijadikan pedoman dalam penyusunan kurikulum, mengingat tipe belajar dari masing-masing tipe kepribadian tidak sama serta dalam pengumpulan data saat wawancara menggunakan media berupa alat perekam dan juga catatan kecil (manuskrip) untuk menjaga kevalidan data yang diperoleh.

2. Guru diharapkan mampu membuat suatu model pembelajaran yang disenangi oleh siswa sehingga mereka tertarik dengan pelajaran matematika, karena salah satu faktor yang mampu menekan tingkat kecemasan belajar yaitu dengan menyukai apa yang dipelajari.

3. Pada langkah memahami masalah, terhadap siswa dengan tipe rational, baik itu kecemasan tinggi maupun rendah sebaiknya guru membimbing atau membiasakan siswa untuk menuliskan hal-hal yang diketahui (syarat cukup) dan hal-hal yang ditanyakan (syarat perlu), demikian juga terhadap siswa tipe idealist, meskipun siswa tipe idealist sudah dapat menuliskan apa yang diketahui dan ditanyakan secara implisit. 


\section{DAFTAR PUSTAKA}

Hartanti \& Judith E.D. (1997). Hubungan Antara Konsep Diri dan Kecemasan Menghadapi Masa Depan dengan Penyesuaian Sosial Anak-anak Madura. Jurnal Psikologi Pendidikan: Anima. 12, 46, 2007.

Keirsey, David. 1984. Please understand me I (temperament sorter model). Promotheus Nemesis Book Company: California.

Keirsey, David. 1988. Please understand me II (temperament character and intelligence). Printed in the United States of America: USA.

Krulik, J \& Rudnik, J. A. 1988. Problem Solving a Handbook for Elementary School Teachers. Temple University. USA.

Munasiah. 2015. Pengaruh Kecemasan Belajar Dan Pemahaman Konsep Matematika Siswa Terhadap Kemampuan Penalaran Matematika. Jurnal Formatif 5(3): 220- 232, 2015 ISSN: 2088-351X.

Polya, George. 1945. How to Solve it, Second Edition. Princeton: Princeton University Press.

Ramirez, Gerard, dkk. 2012. Math Anxiety, Working Memory, And Math Achievement In Early Elementary School. The University of Chicago.

Upu, Hamzah. 2015. Analysis understanding of the SMP student build concept and principle of flatin math. Post graduate program, Makassar state university.

Yuwono, aries. 2010. Profil siswa sma dalam memecahkan Masalah matematika ditinjau Dari tipe kepribadian. Program studi pendidikan matematika Program pascasarjana Universitas sebelas maret: Surakarta. Suryabrata. 